\title{
Outcomes of endoscopic resection of large colorectal lesions subjected to prior failed resection or substantial manipulation
}

\author{
Andrew Emmanuel ${ }^{1,2}$ (D) Shraddha Gulati ${ }^{2} \cdot$ Margaret Burt $^{1,2} \cdot$ Bu'Hussain Hayee $^{2} \cdot$ Amyn Haji $^{1,2}$
}

Accepted: 19 March 2019/Published online: 3 April 2019

(C) The Author(s) 2019

\begin{abstract}
Purpose Injudicious attempts at resection and extensive sampling of large colorectal adenomas prior to referral for endoscopic resection (ER) are common. This has deleterious effects, but little is known about the outcomes following ER. We retrospectively analysed the outcomes of ER of large adenomas previously subjected to substantial manipulation.

Method ER of large ( $\geq 2 \mathrm{~cm}$ ) colorectal adenomas were grouped according to level of manipulation: prior attempted resection, heavy manipulation ( $\geq$ six biopsies or tattoo under lesion) or minimal manipulation ( $<$ six biopsies). Outcomes were compared between groups. Independent predictors of outcomes were identified using multiple logistic regression.

Results Five hundred forty-two lesions (mean size $53.7 \mathrm{~mm}$ ) were included. Two hundred sixty-five (49\%) had been subjected to prior attempted resection or heavy manipulation, 151 (28\%) to minimal manipulation, and $126(23 \%)$ were not previously manipulated. ESD techniques were used more frequently than EMR after substantial manipulation. There were no differences in initial success of ER $(99 \%, 98 \%, 98 \%, p=0.71)$. Prior attempted resection was independently associated with recurrence (OR $2.2,95 \%$ CI $1.1-4.5, p=0.03$ ) and negatively associated with en bloc resection (OR $0.29,95 \%$ CI $0.1-0.7, p=0.004$ ). Regardless of level of prior manipulation, there were no differences in sustained endoscopic cure with $>95 \%$ of patients overall free from recurrence and avoiding surgery at last follow-up.

Conclusion There is a substantial burden of injudicious lesion manipulation before referral, which makes recurrence more likely and en bloc resection less likely. However, with appropriate expertise, sustained successful endoscopic treatment is achievable for the vast majority of patients treated in a specialist unit.
\end{abstract}

Keywords Colorectaladenoma $\cdot$ Endoscopic resection $\cdot$ Endoscopic submucosaldissection $\cdot$ Endoscopic mucosal resection $\cdot$ Prior attempts

\section{Introduction}

Endoscopic resection (ER) of large colorectal adenomas allows organ preserving curative treatment for the vast majority of patients. It has been shown to be safe and effective and is practised throughout the world in the form of endoscopic mucosal resection (EMR) and, in certain specialist centres, in the form of endoscopic submucosal dissection (ESD) $[1,2]$. Although EMR and piecemeal EMR (pEMR) are associated

Andrew Emmanuel aemmanuel@nhs.net

1 Department of Colorectal Surgery, King's College Hospital NHS Foundation Trust, London, UK

2 King's Institute of Therapeutic Endoscopy, King's College Hospital NHS Foundation Trust, London, UK with a significant rate of residual or recurrent adenoma, this can almost always be treated with further ER thereby allowing most patients to avoid surgery [3].

However, there are significant differences in practice between eastern and western expert centres. In Japan, experts advocate the use of magnification colonoscopy and chromoendoscopy for in vivo diagnosis of lesions to guide the choice of resection technique and stress the importance of avoiding unnecessary biopsy of lesions to prevent submucosal fibrosis [4]. Japanese experts also routinely perform ESD, whereas few western centres have incorporated ESD into their standard practice. Expertise in lesion assessment and appropriate lesion selection among western endosocopists is likely to be very different, and many patients in western practice are referred to expert centres after prior injudicious failed attempts at resection or heavy manipulation in the form of extensive tissue sampling or injection of tattoo into the base 
of the lesion. The resulting profound submucosal fibrosis makes ER challenging and increases the risk of complications [5-9].

Despite this, little is known about the scope of the problem of prior heavy manipulation and the outcomes of ER of these challenging lesions. Several small series have examined the feasibility of ER for residual or recurrent lesions after an initial $\mathrm{ER}$, demonstrating that this can successfully be performed in the majority of cases [10-15]. However, many of these series examine the use of only a single technique or are reports from expert eastern centres using only ESD. There are very few data comparing outcomes between patients subjected to substantial prior manipulation and those with minimal manipulation, and no such comparative studies from western units using both EMR and ESD techniques, which is useful to aid resection of these challenging lesions [14, 16].

In this study, we aimed to report the outcomes of ER of large $(\geq 2 \mathrm{~cm}$ ) colorectal adenomas previously subjected to prior attempted resection, extensive biopsy sampling or tattoo placed beneath the base of the lesion and to compare outcomes between these patients and those subjected to minimal manipulation $(<$ six biopsies).

\section{Materials and methods}

\section{Setting}

Our unit is a tertiary referral service for ER of colorectal lesions. We retrospectively analysed all patients identified from a prospectively maintained database of resections between January 2010 and August 2017. Only ERs of lesions $20 \mathrm{~mm}$ or larger were included.

\section{Procedures}

Our approach to assessment and resection has been previously described $[17,18]$. Procedures were generally performed using conscious sedation and analgesia with intravenous midazolam and fentanyl administered by the endoscopist, and patients were discharged home on the day of the procedure.

Lesions were assessed with chromoendsocopy using indigo carmine and magnification colonoscopy (colonoscopes: CF-H260AZL Olympus, Tokyo, Japan and EC-600Z, Fujifilm, Düsseldorf, Germany) and classified according to Kudo pit pattern and vascular pattern (Showa classification) $[19,20]$. Selected lesions were also evaluated with variable high-frequency miniprobe ultrasound (Fujifilm) to evaluate for submucosal invasion. All lesions were considered for endoscopic resection except those with invasive cancer $>\mathrm{T} 1$ (Kudo type Vn pit pattern, sparse vascular pattern, at least muscularis propria invasion on high-frequency miniprobe colonoscopic ultrasound) for which surgery was advised.
The techniques used for resection included ESD, hybrid ESD and EMR or piecemeal EMR (pEMR). The decision for resection technique was based on the patient and lesion characteristics specific to each, bearing in mind our general considerations when undertaking ER [21]. Figure 1 shows examples of heavy prior manipulation and treatment decisions.

EMR and piecemeal endoscopic mucosal resection (pEMR) were performed using a sequential injection and resection technique. The submucosal injection consisted of succinylated gelatine (Gelofusine; B. Braun, Crissier, Switzerland) with adrenaline diluted to $1: 100,000$ and dyed with methylene blue or indigo carmine. A variety of snare types as appropriate to the lesion was used. ESD was performed using an Olympus PCF Q260JL with ST distal hood (Fujifilm) and the FlushKnife (Fujifilm). The ERBE VIO 300D electrosurgery device (Erbe Elekromedezin, Tübingen, Germany) was used for all procedures with appropriate settings depending on the resection technique. For lesions with profound submucosal fibrosis, argon plasma coagulation (APC) was sometimes used as an adjunctive measure after resection of visible adenoma (not to ablate visible residual tissue), although this was dependent on the endoscopist's preference at the time of resection.

Patients underwent surveillance endoscopy at 3-6 months and 12 months, and thereafter were placed on a surveillance program as per national guidelines for adenoma surveillance if appropriate [22].

\section{Data collection}

Data collected included patient demographics, previous manipulation in the form of prior attempts at resection, biopsy sampling or tattoo placed under the lesion, lesion location, size, morphology, Kudo pit pattern, high-frequency miniprobe ultrasound findings, type of resection, previous intervention, achievement of en bloc resection, intraprocedural bleeding, use of adjunctive argon photocoagulation, complications, histopathology findings, recurrence, treatments for recurrence and any surgery.

\section{Definitions}

Prior attempts at resection included any prior endoscopic or surgical (transanal resection, transanal endoscopic microsurgery or transanal minimally invasive surgery) attempt. Heavy manipulation was defined as $\geq$ six biopsies or tattoo placed under the lesion (tattoo had to be visualised in the submucosa directly beneath at least part of the lesion to be included) and minimal manipulation zero to five biopsies. For invasive cancer, invasion $\geq 1000 \mu \mathrm{m}$ from the muscularis mucosa was 


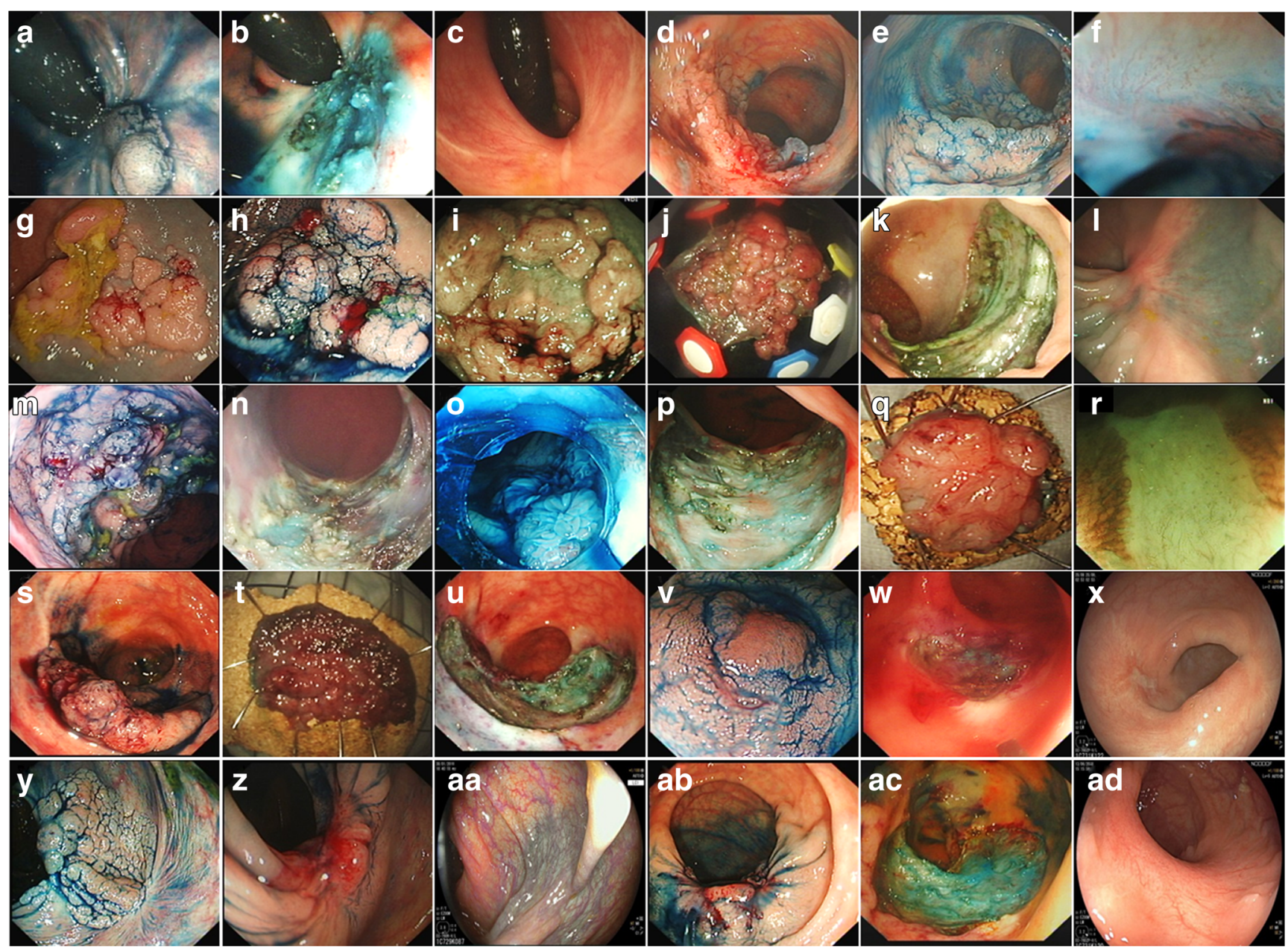

Fig. 1 Examples of heavy prior manipulation, endoscopic treatment and outcome. a-f A low rectal lesion encroaching on the anal canal which was previously subjected to transanal endoscopic microsurgery (TEM). Initially successfully treated by piecemeal endoscopic mucosal resection (pEMR) with no recurrence after 12 months (c). However, 5 years later, the patient is found to have a large recurrent laterally spreading tumour (LST) (d, e). A very challenging endoscopic submucosal dissection is performed resulting in en bloc resection and no recurrence at the healed scar (f). g-l A large rectal LST granular mixed nodular type was referred after multiple repeated endoscopies to obtain tissue samples which all showed adenoma. The lesion has had tattoo injected at the base (g) and has multiple large profoundly scarred areas (i), perhaps in keeping with "snare biopsy". ESD was undertaken and en bloc resection achieved (j, k), resulting in a healthy scar with no recurrence at 18 months follow-up (l). $\mathbf{m}-\mathbf{r}$ A low rectal lesion referred after three prior failed attempts at resection. The profound fibrosis is obvious (m), and hybrid ESD is used to resect the lesion (n). A 20-mm recurrence is detected at 12 months (o) which is resected en bloc using $\operatorname{ESD}(\mathbf{p}, \mathbf{q})$ with a resulting scar with no evidence of recurrence at surveillance $(\mathbf{r})$. $\mathbf{s}-\mathbf{x}$ A lesion after prior TEM and multiple attempts at endoscopic resection as well as argon plasma coagulation ablation. Profound scar is evident even before resection (s). En bloc ESD resection is performed $(\mathbf{t}, \mathbf{u})$. Nevertheless, a small recurrence is found at 18 months and resected by hybrid $\operatorname{ESD}(\mathbf{v}, \mathbf{w})$, and then a further recurrence (x), although distant to the healing ulcer from prior resection. $\mathbf{y}-\mathbf{a a}$ An ascending colon LST subjected to multiple prior attempts at resection. Profound scar is clear around the margin of the lesion (y). The lesion is resected by hybrid ESD, but there is a small recurrence embedded in fibrosis (z) which is resected by EMR with a good result at subsequent surveillance (aa). ab-ad A rectal lesion referred after a failed attempt at resection. The lesion is embedded in profound fibrosis (ab) but is successfully resected by hybrid ESD (ac) with no evidence of recurrence at the scar on surveillance (ad) deemed massive submucosal invasion (equating to Kikuchi $\geq \operatorname{sm} 2$ ), generally considered an indication for radical surgery [23]. Recurrence or residual adenoma for this study was defined as any evidence of adenoma occurring at the scar from previous ER at any surveillance endoscopy (examined with magnification chromoendoscopy and NBI). For complications, both medical and procedure-related complications were included. Post-procedure bleeding was considered a complication if it resulted in any presentation to a healthcare professional, including emergency departments or admission to hospital. Any muscle (muscularis propria) injury requiring additional non-routine management, including unplanned or extended antibiotic treatment, unplanned admission to hospital for observation and/or surgery, was considered a complication.

Outcomes included initial successful ER, en bloc resection, complications and adenoma recurrence. 


\section{Statistical analysis}

Results are reported using means and standard deviation for continuous variables and frequencies for categorical variables. Comparisons were made using $t$ test to compare means and $X^{2}$ test to compare categorical variables. Factors associated with outcomes identified as significantly different between groups were sought, and those with $p<0.1$ on univariate analysis were subjected to multiple logistic regression to identify independent associations.

Ethical approval for this study was granted by the National Research Ethics Committee.

\section{Results}

ER was attempted for 580 colorectal lesions $\geq 20 \mathrm{~mm}$. After excluding procedures for recurrent adenomas after initial resection at our institution, 532 of 542 lesions (98\%) were successfully resected. The mean lesion size was $53.7 \mathrm{~mm} \pm$ $29.6 \mathrm{~mm}$. Mean patient age was 71.4 years.

Two hundred sixty-five lesions (49\%) had been subjected to prior failed attempts at resection or heavy manipulation, $151(28 \%)$ to minimal manipulation, and $126(23 \%)$ were not previously manipulated. Table 1 shows the number of prior attempts at resection for all lesions, including those subjected to both transanal surgery and endoscopic therapy. The mean number of prior attempts at resection was 1.5.

Table 2 shows the patient and lesion characteristics according to the level of prior manipulation. Lesions subjected to prior failed attempts at resection were larger than those with minimal sampling (58.6 mm versus $45.2 \mathrm{~mm}, p<0.001$ ) as were those with heavy manipulation compared to minimal sampling $(65.7 \mathrm{~mm}$ versus $45.2 \mathrm{~mm}, p<0.001)$. Prior attempts at resection were more common for rectal lesions compared to more proximal lesions, and flat lesions were more

Table 1 Type and total number of previous attempts at resection (some patients had both prior transanal surgery and endoscopic treatment)

\begin{tabular}{lr}
\hline Prior manipulation & $N$ \\
\hline Failed snare resection & \\
1 attempt & 81 \\
2 attempts & 20 \\
3 attempts & 4 \\
4 attempts & 1 \\
Transanal surgery (TAR/TEM) & \\
1 TAR/TEM & 13 \\
2 TAR/TEM & 6 \\
3 TAR/TEM & 3 \\
4 TAR/TEM & 2 \\
\hline
\end{tabular}

TAR transanal resection (surgical), TEM transanal endoscopic microsurgery likely to have been subjected to prior failed attempts at resection than those with a polypoid or nodular component (OR $2.37,95 \%$ CI 1.52-3.7, $p<0.001)$. ESD techniques were used more commonly than EMR to resect lesions after prior attempts at resection compared to those with minimal manipulation (OR 2.2, 95\% CI 1.3-3.5, $p=0.002$ ) and those with heavy manipulation compared to minimal manipulation (OR $1.8,95 \%$ CI $1.1-2.9, p=0.01$ ).

There were no differences in the rates of successful initial ER between groups (Table 3). However, en bloc resection was significantly less likely in those with prior attempts at resection compared to those with minimal manipulation (OR 0.2, $95 \%$ CI $0.1-0.4, p<0.001$ ) as well as compared to those with heavy manipulation (OR $0.3,95 \%$ CI $0.2-0.7, p<0.001$ ). Patients with prior heavy manipulation were significantly more likely to experience complications than those with minimal prior manipulation (OR 4.6, 95\% CI 1.6-13.4, $p<$ 0.001 ), although there were no differences between those with prior failed attempts at resection compared to those with minimal manipulation (OR 1.6, 95\% CI 0.4-6.6, $p=0.55$ ).

Adenoma recurrence or residual adenoma was significantly more likely for those with prior failed attempts at resection compared to those with minimal manipulation (OR 4.0, 95\% CI 2.1-7.6, $p<0.001)$ and for those with heavy manipulation compared to minimal manipulation (OR 2.0, 95\% 1.1-3.8, $p<0.001)$.

There were no differences between groups in the proportion of patients ultimately requiring surgery for any reason $(p=0.22)$.

Factors associated with outcomes identified as significantly different between groups (complications, en bloc resection and recurrence) were sought and those with $p<0.1$ on univariate analysis were subjected to multiple logistic regression to identify independent associations (Table 4). Prior failed attempt at resection, EMR, large lesion size $(>40 \mathrm{~mm})$ and use of adjunctive APC were all negatively associated with en bloc resection, while ESD and a polypoid component were independently associated with a higher chance of en bloc resection. Recurrence was independently associated with prior failed attempts at resection, piecemeal resection, large lesion size ( $>40 \mathrm{~mm}$ ) and use of adjunctive APC.

Most recurrences were successfully treated endoscopically and after a median follow-up of 13 months (range 396 months), and the proportion of patients with initial successful ER and without massive submucosal invasion who were free from recurrence and had avoided surgery at last follow-up was similar between all groups and was over $95 \%$ overall.

\section{Discussion}

Submucosal fibrosis makes ER more challenging and may increase the risk of complications. Several series have 
Table 2 Comparison of patient and lesion characteristics according to degree of prior manipulation

\begin{tabular}{|c|c|c|c|c|}
\hline & \multicolumn{3}{|c|}{ Degree of manipulation } & \multirow[b]{2}{*}{$p$ value } \\
\hline & Failed attempt & $\begin{array}{l}\text { Heavy } \\
\text { manipulation }\end{array}$ & $\begin{array}{l}\text { Minimal/no } \\
\text { manipulation }\end{array}$ & \\
\hline Age (mean, years) & 72.6 & 71.9 & 70.6 & 0.21 \\
\hline Male sex & $62(56.4 \%)$ & $84(54.2 \%)$ & $153(55.2 \%)$ & 0.94 \\
\hline Size (mean, mm) & 59.0 & 65.5 & 45.2 & $<0.001$ \\
\hline \multicolumn{5}{|l|}{ Location } \\
\hline Right colon & $28(25.5 \%)$ & $48(30.9 \%)$ & $119(43.0 \%)$ & \multirow[t]{3}{*}{$<0.001$} \\
\hline Left colon & $36(32.7 \%)$ & $57(36.8 \%)$ & $100(36.1 \%)$ & \\
\hline Rectum & $46(41.8 \%)$ & $50(32.3 \%)$ & $58(20.9 \%)$ & \\
\hline \multicolumn{5}{|l|}{ Morphology } \\
\hline Is/Isp & $5(4.6 \%)$ & $21(13.6 \%)$ & $78(28.2 \%)$ & \multirow[t]{5}{*}{$<0.001$} \\
\hline LST G H & $73(66.4 \%)$ & $67(43.2 \%)$ & $118(42.6 \%)$ & \\
\hline LST G MN & $30(27.3 \%)$ & $61(39.4 \%)$ & $70(25.3 \%)$ & \\
\hline LST NG & $2(1.8 \%)$ & $6(3.9 \%)$ & $9(3.3 \%)$ & \\
\hline Submucosal & $0(0 \%)$ & $0(0 \%)$ & $2(0.7 \%)$ & \\
\hline \multicolumn{5}{|l|}{ Morphology } \\
\hline Polypoid & $35(31.8 \%)$ & $82(52.9 \%)$ & $147(53.1 \%)$ & \multirow[t]{2}{*}{$<0.001$} \\
\hline Flat & $75(68.2 \%)$ & $73(47.1 \%)$ & $130(46.9 \%)$ & \\
\hline \multicolumn{5}{|l|}{ Technique } \\
\hline EMR & $74(67.3 \%)$ & $110(71.0 \%)$ & $225(81.2 \%)$ & \multirow[t]{2}{*}{0.004} \\
\hline ESD/hybrid ESD & $36(32.7 \%)$ & $45(29.0 \%)$ & $52(18.8 \%)$ & \\
\hline \multicolumn{5}{|l|}{ Adjunctive APC } \\
\hline Yes & $45(40.9 \%)$ & $23(14.8 \%)$ & $21(7.6 \%)$ & \multirow[t]{2}{*}{$<0.001$} \\
\hline No & $65(59.1 \%)$ & $132(85.2 \%)$ & $256(92.4 \%)$ & \\
\hline \multicolumn{5}{|l|}{ Final histopathology } \\
\hline Adenoma & $102(92.7 \%)$ & $130(83.9 \%)$ & $229(82.7 \%)$ & \multirow[t]{4}{*}{0.06} \\
\hline $\mathrm{SSA} / \mathrm{L}$ & $3(2.7 \%)$ & $9(5.8 \%)$ & $20(7.2 \%)$ & \\
\hline Submucosal invasive cancer & $5(4.6 \%)$ & $16(10.3 \%)$ & $22(7.9 \%)$ & \\
\hline Other & $0(0 \%)$ & $0(0 \%)$ & $6(2.2 \%)$ & \\
\hline
\end{tabular}

identified submucosal fibrosis as an independent predictor of difficult ER, incomplete resection and perforation [5-8, 14, 24-26]. Despite this, there is very little published data on outcomes of ER of lesions subjected to prior substantial manipulation $[14,16]$. The results of this study demonstrate that prior attempts at resection make en bloc resection significantly
Table 3 Comparison of outcomes of endoscopic resection according to degree of prior manipulation

\begin{tabular}{lcccc}
\hline & \multicolumn{2}{l}{ Degree of manipulation } & \\
\cline { 2 - 4 } & Failed attempt & Heavy manipulation & $<$ six biopsies & $p$ value \\
\cline { 2 - 4 } & $109(99.1 \%)$ & $152(98.1 \%)$ & $271(97.8 \%)$ & 0.71 \\
Successful initial resection & $16(14.6 \%)$ & $52(33.6 \%)$ & $114(41.2 \%)$ & $<0.001$ \\
En bloc resection & $3(2.7 \%)$ & $12(7.8 \%)$ & $5(1.8 \%)$ & $<0.001$ \\
Complications & $0(0.0 \%)$ & $7(4.6 \%)$ & $2(0.7 \%)$ & 0.03 \\
Perforation & $7(6.4 \%)$ & $9(5.8 \%)$ & $28(10.1 \%)$ & 0.22 \\
Requiring surgery (any reason) & $27(28.1 \%)$ & $21(15.7 \%)$ & $18(8.3 \%)$ & $<0.001$ \\
Recurrence & $84(96.6 \%)$ & $124(96.9 \%)$ & $207(96.3)$ & 0.96 \\
Free from recurrence at last surveillance & $1.5(1-6)$ & $1.2(1-5)$ & $1.1(1-4)$ & $<0.001$ \\
Mean ERs required & a (range) & & &
\end{tabular}

${ }^{\text {a }}$ Including primary treatment and ER for subsequent recurrence, Mann-Whitney test $E R$ endoscopic resection 


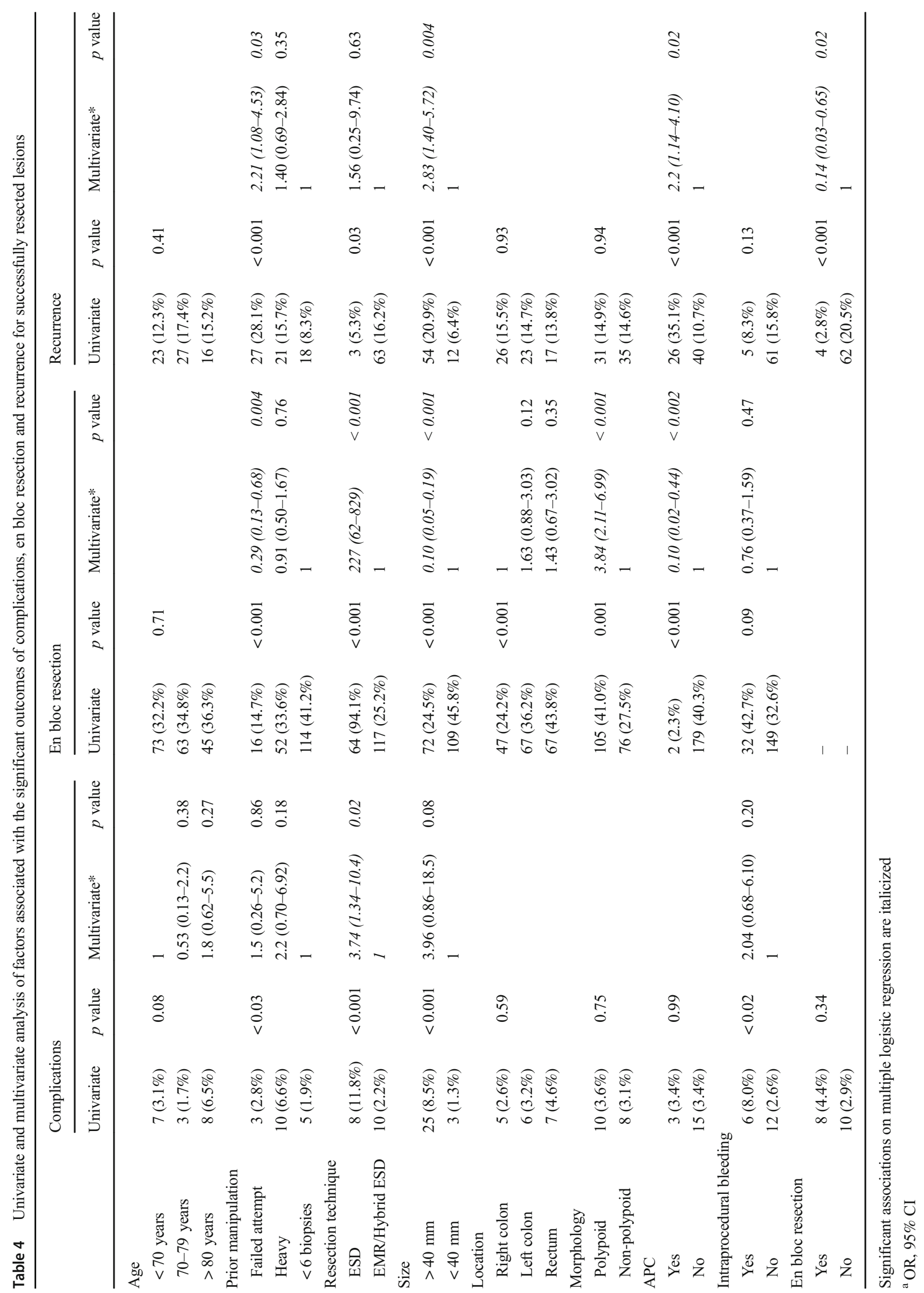


less likely and also increase the risk of recurrent or residual adenoma. They also require the use of more specialised techniques (ESD in our unit) more frequently than lesions with minimal manipulation. Nevertheless, with the necessary expertise and experience, similar proportions (>95\%) of patients are free from recurrence and have avoided surgery at the time of their last surveillance.

The scope of the problem is difficult to define because of limited published data as well as the significant differences in practice in endoscopic assessment and resection between eastern and western endoscopists. Guidelines in Japan are very clear on the importance of in vivo optical assessment, frequently with the aid of magnification endoscopy, and the avoidance of even minimal biopsy sampling [4]. On the other hand, whilst western guidelines also caution against biopsy sampling (albeit less assertively), lesion assessment among general western endoscopists tends to be less standardised and consistent with a variety of descriptive terms used and perhaps a lack of awareness of the true risk of covert malignancy in different morphological sub-types of large colorectal lesions $[27,28]$. This can lead to either injudicious attempts at resection or unnecessary biopsy sampling. Nevertheless, there is little indication of the proportion of patients referred to western expert centres after such attempts or heavy prior manipulation. Although it is almost never reported in the Japanese literature, it is certainly rare with one study reporting that only $7 \%$ of patients had prior ER and only $9 \%$ prior biopsy sampling [6]. From a western perspective, an early series from the Australian Colonic EMR (ACE) study reported that $11 \%$ of patients had undergone previous attempts at endoscopic resection, which was an independent risk factor for failure of endoscopic resection, and a more recent series from the same group reported that 82 of $641(13 \%)$ lesions in the whole cohort had been subjected to prior attempted resection and a higher proportion had been biopsied [16, 29]. Other western reports are scarce. In the current study, we found very high levels of prior heavy manipulation in a large cohort of patients undergoing ER at a western expert centre. Almost half of the lesions had been subjected to prior substantial manipulation with many subjected to (often multiple) prior attempts at resection.

These high levels of prior manipulation undoubtedly affect the difficulty and outcomes of ER with far lower en bloc resection rates achievable for those with prior failed attempts at resection, in keeping with the results from other expert centres, and significantly higher recurrence rates $[5,8,14]$.

Despite this, and in contrast to other studies, the level of prior manipulation did not affect initial rates of successful resection or the proportion of patients ultimately subjected to surgery. Moreover, similarly high levels of long-term success were achieved regardless of level of prior manipulation with over $95 \%$ of patients who did not have invasive adenocarcinoma remaining free from recurrence and avoiding surgery at last follow-up. However, this success comes with the burden of more procedures ultimately required to treat those with substantial prior manipulation when ER for recurrence is taken into account.

Kim et al. reported higher recurrence and lower rates of en bloc resection after ER of prior manipulated lesions compared to naïve lesions. Although we also found that recurrence was more likely after a failed attempt at resection, this was less frequent than that reported by Kim et al. (53.8\% versus $28.1 \%$ ). A potential explanation is suggested by the fact that in $50 \%$ of lesions subjected to prior snare resection, Kim et al. report the use of APC to ablate visible residual adenoma [14]. We generally use APC as adjunctive therapy after complete resection of visible adenoma, following a similar rational to those using snare tip soft coagulation after complete adenoma removal [16]. The lower recurrence in our study could also be explained by our treatment strategy, a pragmatic combination of eastern and western practices of assessment and resection which we have previously reported [17]. ESD techniques were used significantly more frequently in the resection of lesions after failed attempts at resection which, along with the routine examination of the post-resection defect with magnification, may help to ensure complete removal of visible adenoma. Recurrence in this study was similar to that reported by Tate et al. who found recurrence in $22 \%$ of non-lifting lesions at the first surveillance [16].

ESD is not commonly performed in most western specialist centres. Although some western experts would argue that ESD has very limited applications, some have found the technique useful to aid resection of previously attempted or manipulated lesions by dissecting scarred areas or performing enough dissection to allow snare capture of a scarred area $[15,30,31]$. For this reason, and the fact that prior manipulation is probably more common in western practice, we believe that it is important to consider the outcomes of lesions subjected to prior attempts or heavy manipulation treated using the "real-world" approach adopted by a modern western expert centre. This provides valuable data on expected outcomes for these patients. It may be possible in some Japanese expert centres to treat all these lesions with a primary ESD strategy, but in western centres, even those using ESD, it is far more likely that a variety of techniques will be employed to achieve clearance in these difficult lesions. Sub-analysing groups according to whether they were ultimately treated with ESD, hybrid ESD or pEMR would, in our view, give a false sense of the practicalities and outcomes of treating these challenging cases.

After multivariate analysis, heavy manipulation was not independently associated with failure to achieve en bloc resection or with recurrence, unlike prior attempted resection. It is possible that adequate adenoma clearance is achieved in cases after heavy manipulation with the use of techniques such as magnification to examine the resection defect, increased 
experience with EMR and employing ESD techniques in some cases, whereas these measures are not as effective in the presence of the degree of fibrosis encountered in previously attempted lesions.

It is interesting to note that "flat" and rectal lesions were more likely to have been subjected to prior failed attempts at resection, and few lesions had escaped biopsy sampling. This may reflect the limitations in lesion assessment and characterisation among western compared to eastern endoscopists, where these flat or rectal lesions are erroneously judged to be resectable before the true extent or difficulty of ER is appreciated, and almost all large lesions are sampled in an attempt to confirm or exclude adenocarcinoma without realising the effect on subsequent ER.

\section{Limitations}

This study is limited by its retrospective design. The degree of submucosal fibrosis encountered was not prospectively classified. However, we aimed to determine outcomes for lesions subjected to prior substantial manipulation and not outcomes where submucosal fibrosis is encountered. We used minimal manipulation as a comparator group rather than no manipulation. However, we believe that it is more important to define outcomes for advanced endoscopic resection in standard specialist practice and the reality, as shown by these results, is that few large lesions escape insult in the form of injudicious attempts at resection, biopsy or poorly placed tattoo. A comparator group of completely naïve lesions would provide limited information of value to the practising advanced endoscopist.

In conclusion, almost half the lesions in a large western series of colorectal ER had been subjected to prior failed attempts at resection or heavy manipulation, while few lesions escape biopsy sampling. After prior attempts at resection, patients are less likely to have en bloc resection and are more likely to experience recurrence. Nevertheless, in an expert centre, the vast majority of patients can be successfully treated with ER. There is an urgent need to improve general lesion assessment and characterisation in western practice to guide appropriate decision making and referral.

\section{Compliance with ethical standards}

Ethical approval for this study was granted by the National Research Ethics Committee.

Conflict of interest The authors declare that they have no conflict of interest.

Open Access This article is distributed under the terms of the Creative Commons Attribution 4.0 International License (http:// creativecommons.org/licenses/by/4.0/), which permits unrestricted use, distribution, and reproduction in any medium, provided you give appropriate credit to the original author(s) and the source, provide a link to the Creative Commons license, and indicate if changes were made.

\section{References}

1. Hassan C, Repici A, Sharma P, Correale L, Zullo A, Bretthauer M, Senore C, Spada C, Bellisario C, Bhandari P, Rex DK (2016) Efficacy and safety of endoscopic resection of large colorectal polyps: a systematic review and meta-analysis. Gut 65:806-820. https://doi.org/10.1136/gutjnl-2014-308481

2. Akintoye E, Kumar N, Aihara H, Nas H, Thompson CC (2016) Colorectal endoscopic submucosal dissection: a systematic review and meta-analysis. Endosc Int Open 4:E1030-E1044. https://doi. org $/ 10.1055 / \mathrm{s}-0042-114774$

3. Moss A, Williams SJ, Hourigan LF, Brown G, Tam W, Singh R, Zanati S, Burgess NG, Sonson R, Byth K, Bourke MJ (2015) Longterm adenoma recurrence following wide-field endoscopic mucosal resection (WF-EMR) for advanced colonic mucosal neoplasia is infrequent: results and risk factors in 1000 cases from the Australian colonic EMR (ACE) study. Gut 64:57-65. https://doi. org/10.1136/gutjnl-2013-305516

4. Tanaka S, Kashida H, Saito Y, Yahagi N, Yamano H, Saito S, Hisabe T, Yao T, Watanabe M (2015) JGES guidelines for colorectal endoscopic submucosal dissection/endoscopic mucosal resection. Dig Endosc 27:417-434

5. Lee SP, Kim JH, Sung I-K, Lee S-Y, Park HS, Shim CS, Han HS (2015) Effect of submucosal fibrosis on endoscopic submucosal dissection of colorectal tumors: pathologic review of 173 cases. J Gastroenterol Hepatol 30:872-878. https://doi.org/10.1111/jgh. 12886

6. Hayashi N, Tanaka S, Nishiyama S, Terasaki M, Nakadoi K, Oka S, Yoshihara M, Chayama K (2014) Predictors of incomplete resection and perforation associated with endoscopic submucosal dissection for colorectal tumors. Gastrointest Endosc 79:427-435. https:// doi.org/10.1016/j.gie.2013.09.014

7. Isomoto H, Nishiyama H, Yamaguchi N, Fukuda E, Ishii H, Ikeda K, Ohnita K, Nakao K, Kohno S, Shikuwa S (2009) Clinicopathological factors associated with clinical outcomes of endoscopic submucosal dissection for colorectal epithelial neoplasms. Endoscopy 41:679-683. https://doi.org/10.1055/s-00291214979

8. Matsumoto A, Tanaka S, Oba S, Kanao H, Oka S, Yoshihara M, Chayama K (2010) Outcome of endoscopic submucosal dissection for colorectal tumors accompanied by fibrosis. Scand J Gastroenterol 45:1329-1337. https://doi.org/10.3109/00365521. 2010.495416

9. Han KS, Sohn DK, Choi DH, Hong CW, Chang HJ, Lim S-B, Choi HS, Jeong S-Y, Park J-G (2008) Prolongation of the period between biopsy and EMR can influence the nonlifting sign in endoscopically resectable colorectal cancers. Gastrointest Endosc 67:97-102. https://doi.org/10.1016/j.gie.2007.05.057

10. Zhou P, Yao L, Qin X, Xu M, Zhong Y, Chen W (2009) Endoscopic submucosal dissection for locally recurrent colorectal lesions after previous endoscopic mucosal resection. Dis Colon Rectum 52:305310. https://doi.org/10.1007/DCR.0b013e318197e261

11. Kuroki Y, Hoteya S, Mitani T, Yamashita S, Kikuchi D, Fujimoto A, Matsui A, Nakamura M, Nishida N, Iizuka T, Yahagi N (2010) Endoscopic submucosal dissection for residual/locally recurrent lesions after endoscopic therapy for colorectal tumors. J Gastroenterol Hepatol 25:1747-1753. https://doi.org/10.1111/j.1440-1746.2010. 06331.x

12. Hurlstone DP, Shorthouse AJ, Brown SR, Tiffin N, Cross SS (2008) Salvage endoscopic submucosal dissection for residual or local recurrent intraepithelial neoplasia in the colorectum: a prospective analysis. Color Dis 10:891-897. https://doi.org/10.1111/j.14631318.2008.01510.x

13. Sakamoto T, Mori G, Yamada M, Kinjo Y, So E, Abe S, Otake Y, Nakajima T, Matsuda T, Saito Y (2014) Endoscopic submucosal 
dissection for colorectal neoplasms: a review. World J Gastroenterol 20:16153-16158. https://doi.org/10.3748/wjg.v20.i43.16153

14. Kim HG, Thosani N, Banerjee S, Chen A, Friedland S (2015) Effect of prior biopsy sampling, tattoo placement, and snare sampling on endoscopic resection of large nonpedunculated colorectal lesions. Gastrointest Endosc 81:204-213. https://doi.org/10.1016/j.gie. 2014.08.038

15. Chedgy FJQ, Bhattacharyya R, Kandiah K, Longcroft-Wheaton G, Bhandari P (2016) Knife-assisted snare resection: a novel technique for resection of scarred polyps in the colon. Endoscopy 48:277280. https://doi.org/10.1055/s-0035-1569647

16. Tate DJ, Bahin FF, Desomer L, Sidhu M, Gupta V, Bourke MJ (2018) Cold-forceps avulsion with adjuvant snare-tip soft coagulation (CAST) is an effective and safe strategy for the management of non-lifting large laterally spreading colonic lesions. Endoscopy 50: 52-62. https://doi.org/10.1055/s-0043-119215

17. Emmanuel A, Gulati S, Burt M, Hayee B, Haji A (2018) Combining eastern and western practices for safe and effective endoscopic resection of large complex colorectal lesions. Eur J Gastroenterol Hepatol 30:506-513. https://doi.org/10.1097/MEG. 0000000000001086

18. Emmanuel A, Gulati S, Burt M, Hayee B, Haji A (2018) Using endoscopic submucosal dissection as a routine component of the standard treatment strategy for large and complex colorectal lesions in a Western tertiary referral unit. Dis Colon Rectum 61:743-750. https://doi.org/10.1097/DCR.0000000000001081

19. Kudo S, Tamura S, Nakajima T, Yamano H, Kusaka H, Watanabe H (1996) Diagnosis of colorectal tumorous lesions by magnifying endoscopy. Gastrointest Endosc 44:8-14

20. Wada Y, Kudo S, Kashida H, Ikehara N, Inoue H, Yamamura F, Ohtsuka K, Hamatani S (2009) Diagnosis of colorectal lesions with the magnifying narrow-band imaging system. Gastrointest Endosc 70:522-531. https://doi.org/10.1016/j.gie.2009.01.040

21. Emmanuel A, Gulati S, Burt M, Hayee B, Haji A (2017) Colorectal endoscopic submucosal dissection: patient selection and special considerations. Clin Exp Gastroenterol 10:121-131. https://doi. org/10.2147/CEG.S120395

22. Cairns SR, Scholefield JH, Steele RJ, Dunlop MG, Thomas HJW, Evans GD, Eaden JA, Rutter MD, Atkin WP, Saunders BP, Lucassen A, Jenkins P, Fairclough PD, Woodhouse CRJ, British Society of Gastroenterology, Association of Coloproctology for Great Britain and Ireland (2010) Guidelines for colorectal cancer screening and surveillance in moderate and high risk groups (update from 2002). Gut 59:666-689. https://doi.org/10.1136/gut.2009. 179804

23. Pimentel-Nunes P, Dinis-Ribeiro M, Ponchon T, Repici A, Vieth M, De Ceglie A, Amato A, Berr F, Bhandari P, Bialek A, Conio M, Haringsma J, Langner C, Meisner S, Messmann H, Morino M, Neuhaus H, Piessevaux H, Rugge M, Saunders BP, Robaszkiewicz M, Seewald S, Kashin S, Dumonceau J-M, Hassan C, Deprez PH (2015) Endoscopic submucosal dissection:
European Society of Gastrointestinal Endoscopy (ESGE) guideline. Endoscopy 47:829-854. https://doi.org/10.1055/s-0034-1392882

24. Mizushima T, Kato M, Iwanaga I, Sato F, Kubo K, Ehira N, Uebayashi M, Ono S, Nakagawa M, Mabe K, Shimizu Y, Sakamoto N (2015) Technical difficulty according to location, and risk factors for perforation, in endoscopic submucosal dissection of colorectal tumors. Surg Endosc 29:133-139. https://doi.org/ 10.1007/s00464-014-3665-9

25. Sato K, Ito S, Kitagawa T, Kato M, Tominaga K, Suzuki T, Maetani I (2014) Factors affecting the technical difficulty and clinical outcome of endoscopic submucosal dissection for colorectal tumors. Surg Endosc 28:2959-2965. https://doi.org/10.1007/s00464-0143558-y

26. Iacopini F, Saito Y, Bella A, Gotoda T, Rigato P, Elisei W, Montagnese F, Iacopini G, Costamagna G (2017) Colorectal endoscopic submucosal dissection: predictors and neoplasm-related gradients of difficulty. Endosc Int Open 5:E839-E846. https://doi.org/ 10.1055/s-0043-113566

27. Rutter MD, Chattree A, Barbour JA, Thomas-Gibson S, Bhandari P, Saunders BP, Veitch AM, Anderson J, Rembacken BJ, Loughrey MB, Pullan R, Garrett WV, Lewis G, Dolwani S (2015) British Society of Gastroenterology/Association of Coloproctologists of Great Britain and Ireland guidelines for the management of large non-pedunculated colorectal polyps. Gut 64:1847-1873. https:// doi.org/10.1136/gutjnl-2015-309576

28. Bourke M (2009) Current status of colonic endoscopic mucosal resection in the west and the interface with endoscopic submucosal dissection. Dig Endosc 21(Suppl 1):S22-S27. https://doi.org/10. 1111/j.1443-1661.2009.00867.x

29. Moss A, Bourke MJ, Williams SJ, Hourigan LF, Brown G, Tam W, Singh R, Zanati S, Chen RY, Byth K (2011) Endoscopic mucosal resection outcomes and prediction of submucosal cancer from advanced colonic mucosal neoplasia. Gastroenterology 140:19091918. https://doi.org/10.1053/j.gastro.2011.02.062

30. Azzolini F, Camellini L, Sassatelli R, Sereni G, Biolchini F, Decembrino F, De Marco L, Iori V, Tioli C, Cavina M, Bedogni G (2011) Endoscopic submucosal dissection of scar-embedded rectal polyps: a prospective study (Esd in scar-embedded rectal polyps). Clin Res Hepatol Gastroenterol 35:572-579. https://doi. org/10.1016/j.clinre.2011.04.013

31. Fuccio L, Repici A, Hassan C, Ponchon T, Bhandari P, Jover R, Triantafyllou K, Mandolesi D, Frazzoni L, Bellisario C, Bazzoli F, Sharma P, Rösch T, Rex DK (2018) Why attempt en bloc resection of non-pedunculated colorectal adenomas? A systematic review of the prevalence of superficial submucosal invasive cancer after endoscopic submucosal dissection. Gut 67:1464-1474. https://doi. org/10.1136/gutjnl-2017-315103

Publisher's note Springer Nature remains neutral with regard to jurisdictional claims in published maps and institutional affiliations. 